\title{
First trimester maternal upper arm circumference correlated to placental size and neonatal anthropometry
}

Noroyono Wibowo, Rima Irwinda, Lazuardy Rachman

Check for updates

pISSN: 0853-1773 • elSSN: 2252-8083 https://doi.org/10.13181/mji.oa.192950 Med J Indones. 2020;29:38-41

Received: June 19, 2018 Accepted: December 10, 2019

Authors' affiliations:

Department of Obstetrics and Gynecology, Faculty of Medicine, Universitas Indonesia, Cipto Mangunkusumo Hospital, Jakarta, Indonesia

\section{Corresponding author:}

Rima Irwinda

Department of Obstetrics and

Gynecology, Faculty of Medicine, Universitas Indonesia, Cipto

Mangunkusumo Hospital, Jalan Pangeran

Diponegoro No. 71, Kenari, Senen,

Central Jakarta 10430, DKI Jakarta, Indonesia

Tel/Fax: +62-21-1500135

E-mail: rima.irwinda@yahoo.com

\begin{abstract}
BACKGROUND First maternal nutrition, represented by anthropometrics, is an important factor for fetal growth. This study aimed to determine the correlation between maternal nutritional status of first trimester pregnant women with placental size and neonatal anthropometry.
\end{abstract}

METHODS A retrospective cohort study $(\mathrm{N}=134)$ was conducted in Jakarta and Riau during August-September 2017. Correlation between first trimester maternal nutritional status, placental size (placental weight and volume), and neonatal anthropometry (birth weight, birth length, head circumference, and abdominal circumference) were examined using Spearman's correlation test.

RESULTS High maternal body mass index and upper arm circumference (UAC) are weakly correlated with high birth weight $(r=0.281, p<0.001$ and $r=0.271, p<0.001)$, birth length $(r=0.176, p=0.022$ and $r=0.238, p=0.002)$, head circumference $(r=0.251$, $p=0.001$ and $r=0.297, p<0.001)$, abdominal circumference $(r=0.227, p=0.003$ and $r$ $=0.226, p=0.003)$, placental weight $(r=0.198, p=0.01$ and $r=0.228, p<0.001)$, and placental volume $(r=0.194, p=0.01$ and $r=0.203, p=0.008)$. In addition, high maternal height is also weakly correlated with high birth weight $(r=0.157, p=0.043)$ and birth length $(r=0.158, p=0.041)$.

CONCLUSIONS UAC can be reliably used to assess the nutritional status of pregnant women and to predict placental and newborn sizes.

KEYWORDS birth weight, maternal nutrition, pregnancy outcome
Maternal undernutrition remains a major health concern in developing countries. It may lead to increased risk of low birth weight and many other pregnancy complications. ${ }^{1,2}$

Anthropometric measurements can be performed to determine the nutritional status of pregnant women by measuring their body weight before pregnancy, body height, body mass index (BMI), and upper arm circumference (UAC). This technique is an easy, low-cost, and noninvasive method for determining nutritional status..$^{3-5}$ In resource-poor settings, where the availability of well-calibrated equipment for body weight and height measurement is limited, UAC can be a useful substitute to assess maternal nutritional status because this parameter reflects muscle and subcutaneous fat mass. Individuals with a high risk of undernutrition tend to have less subcutaneous fat. Therefore, UAC is a reliable factor to reflect changes in muscle mass and determine whether a woman is undernourished. Early detection of maternal undernutrition may allow prompt treatment to improve maternal and neonatal outcome. 
Conditions such as preeclampsia, spontaneous preterm labor, low birth weight, fetal growth restriction, and stillbirth are linked to not only maternal nutritional status but also placental condition. ${ }^{6}$ Placental weight throughout pregnancy is an important determinant of fetal growth and birth weight because it reflects the placental capacity to transfer nutrients and oxygen to the growing fetus. ${ }^{7}$ This study was aimed to determine the correlation of maternal nutritional status, placental size, and neonatal anthropometry in the first trimester of pregnant women.

\section{METHODS}

This cohort retrospective study included 134 term pregnant women who delivered in Budi Kemuliaan Hospital, Jakarta and Arifin Achmad Hospital, Riau from August to September 2017. Subjects were recruited via consecutive sampling with the following inclusion criteria: normal delivery with complete data about maternal characteristics (age, gravida, parity, abortion, gestational age, body weight, body height, UAC), placental weight, placental volume, and neonatal anthropometry (birth weight, birth length, head circumference, abdominal circumference) and informed consent given to participate in the study. Exclusion criteria were as follows: pregnant women with chronic disease, preeclampsia, and gestational diabetes mellitus, and subjects with incomplete data. This study was approved by the Ethics Committee of Universitas Indonesia (No: 715/UN2.F1/ETIK/2017).

Retrospective data of maternal first trimester weight, height, and UAC were obtained from medical records. Maternal BMI was calculated based on maternal weight and height. UAC was defined as the circumference of the nondominant arm and measured at the midpoint between the acromion and olecranon processes. Infant birth weight, birth length, head circumference, abdominal circumference, placental weight, and placental volume were measured by the attending midwife within an hour after delivery. Data were analyzed using SPSS, version 20.0 (IBM Corp, USA). Descriptive statistics were presented as mean and standard deviation for data with normal distribution, and data without normal distribution were presented as median and minimum-maximum range. Spearman's correlation and linear regression were performed to analyze bivariate and multivariate data.

\section{RESULTS}

There were 168 subjects having normal delivery in Budi Kemuliaan Hospital and Arifin Achmad Hospital, 34 of which were excluded due to incomplete data. A total of 134 subjects were included in this study.

Maternal characteristics and first trimester anthropometry are presented in Table 1. Maternal

Table 1. Maternal, infant, placental characteristics and maternal anthropometry in the first trimester

\begin{tabular}{|c|c|}
\hline Characteristics & $\begin{array}{c}\text { Median (min-max), } \\
N=134\end{array}$ \\
\hline Age (years) & $28(18-42)$ \\
\hline \multicolumn{2}{|l|}{ Gravida, n (\%) } \\
\hline Primi & $48(35.8)$ \\
\hline Multi & $86(64.2)$ \\
\hline \multicolumn{2}{|l|}{ Parity, n (\%) } \\
\hline Nulli & $58(43.3)$ \\
\hline Multi & $76(56.7)$ \\
\hline \multicolumn{2}{|l|}{ History of abortus, $\mathrm{n}$ (\%) } \\
\hline None & $111(82.8)$ \\
\hline Present & $23(17.2)$ \\
\hline Gestational age (weeks) & $39(38-41)$ \\
\hline \multicolumn{2}{|l|}{ Mother } \\
\hline Body weight (kg) & $58.5(48-97)$ \\
\hline Body height $(\mathrm{cm})$ & $156(142-176)$ \\
\hline BMI $\left(\mathrm{kg} / \mathrm{m}^{2}\right)$ & $24(18.1-39.9)$ \\
\hline \multicolumn{2}{|l|}{ BMI group, $\mathrm{n}(\%)$} \\
\hline Underweight $(<18.5)$ & $5(3.7)$ \\
\hline Normal (18.5-24.9) & $75(56.0)$ \\
\hline Overweight (25-29.9) & $43(32.1)$ \\
\hline Obesity (>30) & $11(8.2)$ \\
\hline \multicolumn{2}{|l|}{ UAC group, $\mathrm{n}(\%)$} \\
\hline Low $(<23.5)$ & $18(13.4)$ \\
\hline High ( $\geq 23.5)$ & $116(86.6)$ \\
\hline \multicolumn{2}{|l|}{ Infant } \\
\hline Birth weight (g) & $3,200(2,500-4,550)$ \\
\hline \multicolumn{2}{|l|}{ Birth weight group, $\mathrm{n}(\%)$} \\
\hline Normal $(2,500-4,000)$ & $130(97.0)$ \\
\hline High $(>4,000)$ & $4(3.0)$ \\
\hline Birth length $(\mathrm{cm})$ & $48(45-52)$ \\
\hline Head circumference $(\mathrm{cm})$ & $34(32-38)$ \\
\hline Abdominal circumference $(\mathrm{cm})$ & $33(31-35)$ \\
\hline Placental weight (g) & 550 (459-599) \\
\hline Placental volume $\left(\mathrm{cm}^{3}\right)$ & 756 (720-924) \\
\hline
\end{tabular}

$\mathrm{BMI}=$ body mass index; $\mathrm{UAC}=$ upper arm circumference 
Table 2. Correlation of maternal BMI, body height, and UAC with birth characteristics

\begin{tabular}{lcccccc}
\hline \multirow{2}{*}{ Characteristics } & \multicolumn{2}{c}{ Maternal BMI } & \multicolumn{2}{c}{ Body height } & \multicolumn{2}{c}{ UAC } \\
\cline { 2 - 7 } & $r$ & $p$ & $r$ & $p$ & $r$ & $p$ \\
\hline Birth weight & 0.281 & $<\mathbf{0 . 0 0 1}$ & 0.157 & $\mathbf{0 . 0 4 3}$ & 0.271 & $<\mathbf{0 . 0 0 1}$ \\
Birth length & 0.176 & $\mathbf{0 . 0 2 2}$ & 0.158 & $\mathbf{0 . 0 4 1}$ & 0.238 & $\mathbf{0 . 0 0 2}$ \\
Head circumference & 0.251 & $\mathbf{0 . 0 0 1}$ & 0.117 & 0.131 & 0.297 & $<\mathbf{0 . 0 0 1}$ \\
Abdominal circumference & 0.227 & $\mathbf{0 . 0 0 3}$ & -0.025 & 0.745 & 0.226 & $\mathbf{0 . 0 0 3}$ \\
Placental weight & 0.198 & $\mathbf{0 . 0 1}$ & 0.043 & 0.581 & 0.228 & $<\mathbf{0 . 0 0 1}$ \\
Placental volume & 0.194 & $\mathbf{0 . 0 1}$ & 0.027 & 0.724 & 0.203 & $\mathbf{0 . 0 0 8}$ \\
\hline
\end{tabular}

$\mathrm{BMI}=$ body mass index; $\mathrm{UAC}=$ upper arm circumference

median BMI, body height, and UAC were $24 \mathrm{~kg} / \mathrm{m}^{2}$, $156 \mathrm{~cm}$, and $25 \mathrm{~cm}$. Only $3.7 \%$ of the mothers were underweight during the first trimester, whereas $32 \%$ were overweight.

The results of Spearman's correlation between variables were presented in Table 2. High maternal $\mathrm{BMI}$ and UAC were weakly correlated with high birth weight, birth length, head circumference, abdominal circumference, placental weight, and placental volume. In addition, high maternal height was also correlated with high birth weight and birth length, although it showed weak correlation.

\section{DISCUSSION}

Maternal nutritional intake during preconception and pregnancy affects fetal growth and placental metabolism, which can be reflected by the measured maternal BMI, body height, and UAC during the first trimester. 8,9 This study showed that high maternal BMI and UAC were associated with high infant birth weight, birth length, head circumference, abdominal circumference, placental weight, and placental volume. High maternal body height was related to high infant birth weight and birth length. The correlation of these characteristics with UAC was more significant than that with $\mathrm{BMI}$, implying that UAC was a reliable parameter for assessing the nutritional status of pregnant women and could be used to predict placental and infant sizes.

UAC is used as a screening tool to assess malnutrition in children and adults. A low UAC ( $<23.5$ $\mathrm{cm}$ ) among pregnant women is associated with pregnancy complications such as low birth weight and preterm labor. ${ }^{10}$ Studies have stated that maternal UAC has a sensitivity of $92.1 \%$ and a sensitivity of $88.3 \%$ for the detection of maternal protein-energy malnutrition. ${ }^{11}$ UAC can be used to examine the maternal nutritional status, which significantly affects fetal and placental growth, during preconception and pregnancy. ${ }^{9}$ Placental growth can be evaluated by measuring placental weight, which is a strong predictor of birth weight. Placental weight may indicate the placental capacity to transfer oxygen and nutrients to the fetus. ${ }^{12}$

UAC measurement is an easy and cheap modality that has been described since 1994 in several studies reporting the increased risk of preterm labor in pregnant women with a low UAC. ${ }^{10}$ Other studies have also shown that measured UAC is a predictor in assessing the nutritional deficiency and clinical condition of pregnant women. ${ }^{13}$ In Bangladesh, Gernand et al ${ }^{9}$ reported that maternal factors, including UAC are positively correlated with birth weight and placental mass. A similar result was observed in our study, which revealed that UAC was also positively correlated with neonatal anthropometry. This finding suggested that UAC might be used to assess nutritional status during pregnancy and predict placental and fetal sizes. However, the correlation between variables found in this study was weak, so other modalities should be considered to examine maternal nutritional status and newborn condition. The measurement of maternal plasma nutrient level is the most objective method to evaluate maternal macro- and micronutrient adequacy, but this method is costly and inaccessible nationwide. As such, it cannot be applied to a national level. The nature of UAC reflecting muscle mass is hindered in the presence of subcutaneous mass, whose distribution varies with genetics and age. ${ }^{14}$ This condition might explain the low correlation found in this study because only $3.7 \%$ of the subjects were underweight.

This study had several limitations, including bias attributed to secondary data and the absence of data 
about pregnancy-related maternal weight gain and maternal intake, which also affected placental and neonatal outcome. In conclusion, UAC can be reliably used to assess the nutritional status of pregnant women and to predict placental and newborn sizes.

\section{Conflict of Interest}

The authors affirm no conflict of interest in this study.

Acknowledgment

None.

Funding Sources

None.

\section{REFERENCES}

1. Aurangzeb B, Whitten KE, Harrison B, Mitchell M, Kepreotes $\mathrm{H}$, Sidler $\mathrm{M}$, et al. Prevalence of malnutrition and risk of undernutrition in hospitalized children. Clin Nutr. 2012;31(1):35-40.

2. Uauy R, Corvalan C, Casanello P, Kuzanovic J. Intervention strategies for preventing low birthweight in developing countries: importance of considering multiple interactive factors. Nestle Nutr Inst Workshop Ser. 2013;74:31-52.

3. Deierlein AL, Siega-Riz AM, Adair LS, Herring AH. Effects of pre-pregnancy body mass index and gestational weight gain on infant anthropometric outcomes. J Pediatr. 2010;158(2):221-6.

4. Togni FA, Araujo Júnior E, Vasques FA, Moron AF, Torloni MR, Nardozza LM. The cross-sectional area of umbilical cord components in normal pregnancy. Int J Gynaecol Obstet. 2006;96(3):156-61.

5. Ilmonen J, Isolauri E, Poussa T, Laitinen K. Impact of dietary counselling and probiotic intervention on maternal anthropometric measurements during and after pregnancy: a randomized placebo-controlled trial. Clin Nutr. 2010;30(2):15664.

6. Sohlberg S, Mulic-Lutvica A, Lindgren P, Ortiz-Nieto F, Wikström AK, Wikström J. Placental perfusion in normal pregnancy and early and late preeclampsia: a magnetic resonance imaging study. Placenta. 2014;35(3):202-6.

7. Effendi M, Demers S, Giguère $Y$, Forest JC, Brassard N, Girard M, et al. Association between first-trimester placental volume and birth weight. Placenta. 2014;35(2):99-102.

8. Morrison JL, Regnault TR. Nutrition in pregnancy: optimising maternal diet and fetal adaptation to altered nutrient supply. Nutrients. 2016;8(6):342.

9. Gernand AD, Christian P, Paul RR, Shaikh S, Labrique AB, Schulze KJ, et al. Maternal weight and body composition during pregnancy are associated with placental and birth weight in rural Bangladesh. J Nutr. 2012;142(11): 2010-6.

10. Tang AM, Dong K, Deitchler M, Chung M, Maalouf-Manasseh Z, Tumilowicz A, et al. Use of cutoffs for mid-upper arm circumference (MUAC) as an indicator or predictor of nutritional and health-related outcomes in adolescents and adults: a systematic review. Washington: Food and Nutrition Technical Assistance III Project (FANTA); 2013.

11. The Indonesian Basic National Health Survey [Internet]. 2014 [cited 2014 Mar 31]. p. 1-362. Available from: http://terbitan. litbang.depkes.go.id/penerbitan/index.php/blp/catalog/ book/64.

12. Wallace JM, Horgan GW, Bhattacharya S. Placental weight and efficiency in relation to maternal body mass index and the risk of pregnancy complication in women delivering singletons babies. Placenta. 2012;33(8):611-8.

13. Shaikh F, Zeeshan F, Hakeem R, Basit A, Fawwad A, Hussain A. Matenal dietary intake and athropometric measurement of newborn at birth. Open Diabetes J. 2014;7:14-9.

14. Rask-Andersen M, Karlsson T, Ek WE, Johansson Å. Genomewide association study of body fat distribution identifies adiposity loci and sex-specific genetic effects. Nat Commun. 2019;10(339). 